Longzeng Wu, Li-Qun Wei, Yichi Zhang, Tielin Han

\title{
Employee Experienced HPWPs and Job Performance: Roles of Person-Job Fit and Intrinsic Motivation
}

(C) Higher Education Press and Springer-Verlag 2011

\begin{abstract}
The extant research on high performance work practices (HPWPs) mainly focuses on the organization level, with little research exploring employee experienced HPWPs and their impact on individual work outcomes. Whether and how employee experienced HPWPs contribute to individual job performance is investigated in this study, using three waves of data from 318 subordinatesupervisor dyads in three big auto manufacturing companies in China. Results show that HPWPs are positively related to individual job performance. Moreover, this relationship is fully mediated by employee person-job fit and intrinsic motivation.
\end{abstract}

Keywords high performance work practices, person-job fit, intrinsic motivation, job performance

Received September 13, 2010

Longzeng $\mathrm{Wu}(\bowtie)$

School of International Business Administration, Shanghai University of Finance and Economics, Shanghai 200433, China

E-mail: wulongzeng@gmail.com

Li-Qun Wei

Department of Management, Hong Kong Baptist University, Hong Kong, China

E-mail: weiliqun@hkbu.edu.hk

\section{Yichi Zhang}

Department of Organization Management, Guanghua School of Management, Peking University, Beijing 100871, China

E-mail: zyc@gsm.pku.edu.cn

Tielin Han

Department of Organization Management, Guanghua School of Management, Peking University, Beijing 100871, China

E-mail: tielinhan@gmail.com 


\section{Introduction}

Research on high performance work practices (HPWPs) has gained increasing attention during the past two decades (Delery and Doty, 1996; Sun, Aryee and Law, 2007; Takeuchi, Lepak, Wang and Takeuchi, 2007; Takeuchi, Chen and Takeuchi, 2009). A review of the literature indicates significant progress in understanding whether and how HPWPs contribute to firm performance (Appelbaum, Bailey, Berg and Kalleberg, 2000; Arthur, 1994; Bae and Lawler, 2000; Bartel, 2004; Batt, 2002; Guthrie, 2001; Huselid, 1995; MacDuffie, 1995; Sun et al., 2007). There is, however, little research on the relationships between HPWPs and specific work outcomes at the employee level (Wright and Boswell, 2002). A few studies have examined the direct effects of HPWPs on employee work outcomes (Ramsay, Dora and Harley, 2000; Harley, Allen and Sargent, 2007). However, they have rarely explored the underling mechanisms (Liao, Toyo, Lepak and Hong, 2009). The growing adoption of HPWPs and the consequent great impact of HPWPs on employees suggest that it is timely and important for researchers to understand the processes through which HPWPs influence employee outcomes.

Moreover, prior research on HPWPs at the organizational level has largely assumed that HPWPs impact on groups of people or all the employees in a firm rather homogeneously. However, this assumption has recently been challenged (Gerhart, Wright and McMahan, 2000; Wright and Boswell, 2002), which brings about a promising research direction. That is, it will be more meaningful to apply the macro perspective of HPWPs into micro research to better understand how employee experienced HPWPs may influence individual work attitudes and behaviors (Liao et al., 2009).

Accordingly, this study is designed to investigate whether and how employee experienced HPWPs relate to individual work outcomes. To this end, we first examined the link between employee experienced HPWPs and individual job performance. Job performance is a focus of this study because it is one of the most widely studied employee work outcomes and can improve organizational effectiveness (Motowidlo, 2003). Moreover, based on the HPWPs literature, person-job fit, and self-determination theories, we then examined the mediating roles of person-job fit and intrinsic motivation in the relationship between employees' experienced HPWPs and individual job performance. Finally, a three-wave research design was applied to test the hypothesized relationships in an attempt to overcome the limitations of the cross-sectional designs that predominate the HPWPs literature (Sun et al., 2007). The conceptual model of the study is illustrated in Fig. 1. 


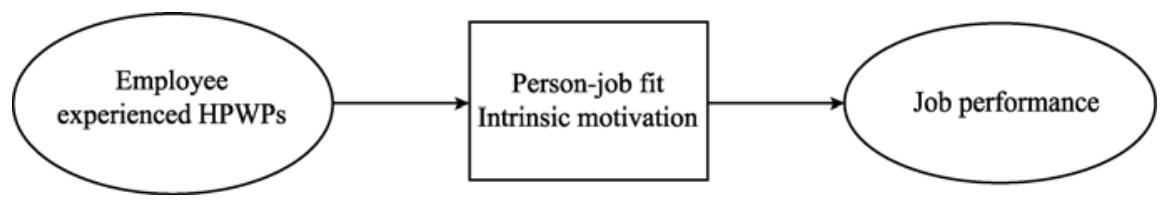

Fig. 1 Conceptual Model of the Study

\section{Theoretical Background and Hypotheses}

\subsection{Employee Experienced HPWPs}

With the thesis that human resources are valuable for business success (Barney and Wright, 1998), many theoretical and empirical studies have been conducted to examine the roles played by human resource practices in organizations (Boxall 1996; Wright and Boswell, 2002; Wright, Dunford and Snell, 2001). Different from the traditional "isolated" view of HRM, these studies have usually taken a "system" view and tested multiple HR practices (Delery and Doty, 1996; Sun et al., 2007). The basic assumption has been that "individual practices can complement, substitute for, or even conflict with other practices... Hence multiple, rather than isolated, practices must be examined"(Wright and Boswell, 2002: 249). Among various types of HR systems, HPWPs are among the most widely examined and are viewed as an alternative to traditional productions systems that are firmly rooted in Fredrick Taylor's scientific management and subsequent Fordist principles. Although researchers have not reached unanimous agreement about how to conceptualize HPWPs, it is widely accepted that HPWPs are "coherent practices that enhance the skills of the workforce, participation in decision making, and motivation to put forth discretionary effort" (Appelbaum et al., 2000: 26).

A review of the literature indicates that prior studies have predominantly taken a macro-level approach and focused on the establishment of HPWPs and their implications for firm-level outcomes (Bartel, 2004; Boxall, 1996; Delery and Doty, 1996; Huselid, 1995; Sun et al., 2007; Wright et al., 2001). Very few studies have ever taken a micro-level approach to investigating the role of employee experienced HPWPs (Liao et al. 2009; Wright and Boswell 2002). One reason for preferring the macro to the micro level in HPWPs research is that HR practices have long been assumed to be invariable across large groups of jobs and individuals within an organization (Wright and Boswell 2002).

However, this assumption has recently been challenged. Research indicates that individual employee's experience of HPWPs does differ from one to another within an organization (Lepak, Liao, Chung and Harden, 2006; Liao et al., 2009). There are mainly two reasons for the differences: First, different employees work 
in different groups, and an organization may in fact implement different HR practices with different work groups; and secondly, even within the same group, group members may be treated differently or have different experiences of the practices in place (Liao et al., 2009; Rousseau, 2005).

Scholars suggest that what really matters to employees are their personally experienced HPWPs rather than a firm's adopted HRM practices, and such experiences can have profound implications for employees' work outcomes (Liao et al., 2009; Wright and Boswell, 2002). In line with these arguments, this study investigated whether and how an employee's experience of HPWPs relates to his or her job performance.

\subsection{Employee Experienced HPWPs and Job Performance}

We argued that employee experienced HPWPs are likely to contribute to individual job performance for two reasons. Firstly, when employees are properly trained and get meaningful assignments and opportunities to participate in decision making (all essential parts of HPWPs), their knowledge, skills and abilities are likely to be advanced (Pfeffer and Veiga, 1999). As the knowledge, skills and abilities are important for task accomplishment, it is to be expected that these employees will usually achieve a better job performance (Becker and Huselid, 1998; Delery and Shaw, 2001).

Secondly, HPWPs imply an investment in employees by the organization (Sun et al., 2007). It has been suggested that employees' experience within an organization, specifically their personal experience of HR practices, shape their beliefs regarding their relationships with the organization, which in turn can significantly impact their work behaviors and attitudes (Guest, 1998). For example, a group led by Tsui (Tsui, Pearce, Porter and Tripoli, 1997) explored the effects of different employee-organization relationship approaches on employee outcomes. Based on the balance between employer-expected employee contributions and employer-offered inducements, they identified four employeeorganization relationship approaches (i.e., mutual investment, overinvestment, underinvestment, and quasi-spot-contract), and found that the mutual investment and overinvestment approaches are more effective than the quasi-spot-contract and underinvestment approaches in generating favorable employee outcomes such as better job performance and organizational citizenship and more affective commitment. Shore and Barksdale (1998) focused on the balance between employee obligations and employer obligations. They similarly found that among four types of exchange relationships - mutual high obligations, mutual low obligations, employee under-obligation, and employee over-obligation-mutual high obligations was the most effective in generating affective commitment, perceptions of good organizational support, career optimism and intent to stay 
with the organization. These findings suggest that when employees perceived high levels of investments from the organization they are likely to contribute more in return. HPWPs provide employees with in-depth training, meaningful assignments, work security and opportunities to participate in decision making, all of which represent investments on the part of the organization. Employees who experience high levels of HPWPs may thus be inclined to reciprocate. Based on the foregoing discussion, we propose the following hypothesis:

H1 Employee-experienced HPWPs are positively related to individual job performance.

\subsection{The Mediating Roles of Person-Job Fit and Intrinsic Motivation}

The relationship between employee-experienced HPWPs and individual job performance can be explained by two factors: work motivation and knowledge, skills and abilities. Huselid (1995) argued that increasing the work motivation of a firm's employees and improving their knowledge, skills and abilities are two key functions of HPWPs. Employees with enhanced knowledge, skill and abilities will tend to fit their jobs better. Therefore, based on Huselid's theoretical arguments, we theorize that HPWPs are likely to promote both person-job fit and work motivation. Moreover, person-job fit and self-determination theories argue that better fit and work motivation can lead to better job performance (Deci and Ryan, 2000, 2002; Kristof, 1996). Combination of these theoretical arguments suggests that it might be fruitful to examine the mediating effects of person-job fit and work motivation in the relationship between employee experienced HPWPs and individual job performance.

Person-Job Fit. The concept of person-job fit is one that is familiar to most organizational researchers. Prior research on person-job fit has identified two different forms of fit: supplies-values (S-V) fit and demands-abilities (D-A) fit. $\mathrm{S}-\mathrm{V}$ fit pertains to whether an employee's desires (goals, interests and preferences) are fulfilled by what the job supplies whereas D-A fit pertains to whether an employee's knowledge, skill, and abilities (KSA) meet the demands of the job (Cable and DeRue, 2002; Edwards, 1991). Based on Huselid's (1995) theoretical arguments on the key functions of HPWPs, the present study focused on D-A fit and examined its role in linking employee experienced HPWPs with individual job performance.

It can be theoretically argued that employee experienced HPWPs should be positively related to person-job fit. This is because, in the first place, the in-depth training and broad involvement policies of HPWPs actively engage employees in skill learning (Kristof,1996), which should not only help them better understand the nature of the job, but also develop job-specific knowledge and abilities, leading to better person-job fit. In addition, well-defined job specifications should also promote person-job fit because they help employees more clearly 
understand the job demands. Research has suggested that an important component of person-job fit is awareness of all of the job's essential factors (Brousseau, 1984). Finally, the pay for performance policy of HPWPs should motivate employees to develop job-specific knowledge, skills and abilities, which should also result in better fit with their jobs.

When an employee's KSA meet the demands of the job, positive responses tend to ensue (Kristof, 1996). There is empirical evidence that the positive responses may include favorable job attitudes, decreased turnover, and better contributions (Caldwell and O'Reilly, 1990; Edwards, 1991). Caldwell and O'Reilly (1990) found that managers' performance is better when their skills and abilities better fit the profile required for the job. The review by Edwards (1991) also indicated that high congruence between the demands of a job and a person's KSA leads to better job performance, greater job satisfaction, and lower turnover intentions. HPWPs should thus enhance job fit, and through that positively influence performance.

H2 Person-job fit mediates the relationship between employee experienced HPWPs and individual job performance.

Intrinsic Motivation. Work motivation has been extensively researched. For example, Deci and Ryan (1985) have proposed two different types of work motivation: intrinsic and extrinsic motivation. Intrinsic motivation refers to initiating a work task for its own sake because it is interesting and satisfying in itself, whereas extrinsic motivation refers to initiating a work task for any external or outside reward such as money. The present study focuses on intrinsic motivation because prior studies have consistently demonstrated that intrinsically motivated employees have better concentration, learning, recall, performance and creativity than those who are extrinsically motivated. (see Deci and Ryan, 2000; Vallerand, 1997 for reviews).

Self-determination theory is a meta-theory widely used in framing motivational studies. According to the theory, the need for autonomy, competence, and relatedness are all fundamental human needs that individuals constantly strive to satisfy (Deci and Ryan, 2000, 2002). Social contexts supporting an individual's experience of autonomy, competence, and relatedness can result in high levels of intrinsic motivation. In contrast, if any of these three psychological needs is thwarted in a social context, the individual will be less intrinsically motivated in that setting (Deci and Ryan, 2000, 2002; Gagné and Deci, 2005). This theory suggests that HPWPs may play a key role in enhancing the intrinsic motivation of employees because they will tend to satisfy their autonomy, competence and relatedness needs. HPWPs encourage employees to actively participate in decision-making and seek out challenges and new possibilities, which should tend to fulfill their need for autonomy. HPWPs also provide employees chances to learn more job-related knowledge and skills and 
encourage them to take responsibility, which should satisfy their competence needs. Finally, HPWPs also tend to fulfill employees' need for relatedness because they help create a supportive work environment in which employees care for and interact smoothly with each other (Sun et al., 2007).

When intrinsic motivation is high, one is more likely to enjoy working, to invest more time and energy in work tasks, and thus to perform them better and more productively (Deci and Ryan, 2000, 2002). Consistent with these theoretical arguments, empirical research has confirmed that intrinsic motivation is positively related to persistence in work tasks, performance quality, and overall performance ratings (Hackman and Oldham, 1980; Piccolo and Colquitt, 2006; Vallerand, 1997). In sum, HPWPs should motivate employees by helping to satisfy their need for autonomy, competence and relatedness, and this should improve their job performance.

H3 Intrinsic motivation mediates the relationship between employee experienced HPWPs and individual job performance.

\section{Methods}

\subsection{Pilot Study}

A 23-item scale developed by Dolery and Doty (1996) was modified and applied to measure employee experienced HPWPs. Response options ranged from 1, "strongly disagree," to 7, "strongly agree." Sample items included: "Extensive training programs are provided for me," "I can decide my way of working on many occasions," and "I am often asked by my supervisor to participate in decisions." Following the commonly used back translation procedure, the scale was translated from English into Chinese and then back translated into English by two independent bilingual individuals to ensure equivalency of meaning (Brislin, 1980).

A pilot study was conducted to assess the psychometric characteristics of this modified scale. The sample for the pilot study consisted of 190 employees from eleven Chinese companies. Among the 190 participating employees, $60.5 \%$ were male, the average age was around 30 years old $(54.2 \%$ were below $29,19.5 \%$ were $30-34,12.1 \%$ were $35-39,7.4 \%$ were $40-44,1.6 \%$ were $45-49$ years old, and $5.3 \%$ were over 50 years old), and the average organizational tenure was 6.02 years (S.D. $=6.85)$.

Exploratory factor analyses were conducted to test the structure of this modified measure. Due to cross-loadings, five items were deleted from the scale. The remaining 18 items loaded onto four factors with eigenvalues greater than 1 : job training, job participation, job specification, and job security. The results of the factor analyses are shown in Table 1. Taken together, the four factors 
Table 1 Exploratory Factor Analyses of Employee Experienced HPWPs

\begin{tabular}{lcccc}
\hline Item & Training & Job & Job & Job \\
& & participation & specification & security
\end{tabular}

1. I normally go through training programs every few years

0.82

2. Extensive training programs are provided for me

3. Formal training programs are offered to me in order to increase my promotability in this organization

4. There were formal training programs to teach me the skills I need to perform my job when I was newcomer

5. I am provided the opportunity to suggest improvements in the way things are done

6. I am often asked by my supervisor to participate in decisions

7. I can decide my way of working on many occasions

8. Superiors keep communications with me open

9. My actual job duties are shaped more by a specific job description than by me

10. My job has an up-to-date job description

11. The job description for my job contains all of the duties I perform

12. Performance appraisals are based on objective results

13. Performance is more often measured with quantifiable results

14. The duties of my job are clearly defined

15. I can expect to stay in the organization for as long as I wish

16. It is difficult for the organization to dismiss me

17. My job security is almost guaranteed

18. If the organization were facing economic problems, I would be the last to get cut

Cronbach's alpha

Eigenvalue

Explained variance (\%)

15.78

2.80

0.88

Note: $1 . n=190$

2. Extraction method: Principal component analysis.

3. Rotation method: Varimax with Kaiser's normalization.

4. Factor loadings below 0.05 have been suppressed. 
explained $67.35 \%$ of the total variance. The alpha values for job training, job participation, job specification, and job security in this study were $0.85,0.85$, 0.88 , and 0.73 , respectively. Given the good results, the modified 18-item scale of employee perceptions was used in the main study.

\subsection{Main Study}

Sample and Procedures. The respondents in the main study were employees of three large auto manufacturing companies (all are joint ventures) in China. HR managers from the companies compiled lists of randomly selected 510 subordinates and their corresponding 510 supervisors from various departments and hierarchical levels. Separate questionnaires were then administered to the subordinates and supervisors. The questionnaires were coded before being distributed, and the HR departments assisted in the recording of the identification numbers to match subordinates' responses with those of their supervisors. Following the commonly used back translation procedure, the scales (expect for the scale of employee experienced HPWPs which has been validated in the pilot study) were translated from English into Chinese and then back translated into English by two independent bilingual individuals to ensure equivalency of meaning (Brislin, 1980). The respondents were informed that the survey aimed to examine HR practices and were assured of the confidentiality of their data. Each participant placed his or her completed survey in a sealed envelope and returned it to a box in the HR department in each company.

Three waves of data collection from two different sources were performed to reduce the potential for common method bias (Podsakoff, MacKenzie, Lee and Podsakoff, 2003). In wave one, questionnaires were administered to all 540 subordinates, and the respondents were asked to provide demographic information and their experienced HPWPs. We received usable responses from 421 of the subordinates at a response rate of $77.9 \%$. Three months later, in wave two, questionnaires were distributed to the 421 subordinates asking them to evaluate their person-job fit and intrinsic motivation. Four of the subordinates had left the company, only 417 received the questionnaires. Usable responses were received from 357 of them at a response rate of $85.6 \%$. Finally, three months after the second-wave survey, in wave three, questionnaires were administrated to the 357 supervisors asking them to evaluate the subordinate's job performance. One supervisor had left the company, only 356 supervisors received the questionnaire. Usable responses were obtained from 318 supervisors, a response rate of $89.3 \%$. After matching the subordinate-supervisor pairs, the final sample consisted of 318 subordinates and their supervisors.

Among the 318 subordinates, $64.5 \%$ were male, the average age was 32.66 years $($ S.D. $=5.66)$, and the average tenure was 4.80 years $($ S.D. $=3.16)$. Most of 
the subordinates were educated to the junior college level or below $3.8 \%$ held a middle school diploma or below, $29.6 \%$ held a high school diploma, $43.1 \%$ held a junior college degree, $21.1 \%$ held a bachelor's degree, and $2.5 \%$ held a postgraduate degree).

Measures. Five-point Likert-type scales ranging from 1 "strongly disagree" to 5 "strongly agree" were used for all measures in this study. The specific measures are described below with their Cronbach alphas, which are also shown on the diagonal in Table 3.

Employee experienced HPWPs. The 18-item scale developed in the pilot scale was used to measure the employee experienced HPWPs. We conducted a CFA using the data from the main sample to further assess this measure. As suggested by Hair, Anderson, Tatham and Black (1998), the overall model's chi-square, the comparative fit index (CFI), the Tucker-Lewis Index (TLI), and the root mean square error of approximation (RMSEA) were used to assess the model's fit. The results indicated that the fit indexes for the four first-order factors plus one second-order factor fell within an acceptable range $\left(\chi^{2}(132)=400.74, p \leqslant 0.01\right.$; RMSEA $=0.080 ; \mathrm{CFI}=0.90$; TLI $=0.89$ ). Cronbach's alpha was 0.81 for job training, 0.83 for job participation, 0.90 for job specification, 0.74 for job security, and 0.92 for the scale as a whole.

Person-job fit. Cable and DeRue's (2002) three-item scale was used to measure person-job fit. The 3 items were: "The match is very good between the demands of my job and my personal skills," "My abilities and training are a good fit with the requirements of my job," and "My personal abilities and education provide a good match with the demands that my job places on me." The Cronbach's alpha of this scale was 0.72 .

Intrinsic motivation. Warr, Cook and Wall's (1979) six-item intrinsic motivation scale was used. The items included: "I try to think of ways of doing my job effectively," "I feel unhappy when my work is not up to my usual standard," and "I take pride in doing my jobs as well as I can." The Cronbach's alpha of this scale was 0.87 .

Job performance. The five-item scale originally developed by Williams and Anderson (1991) and later used by Hui, Law and Chen (1999) in a Chinese context was used to measure job performance. Sample items included: "This employee always completes the duties specified in his/her job description," "This employee meets all the formal performance requirements of the job," and "This employee fulfills all responsibilities required by his/her job." The scale's reliability was 0.85 .

Control variables. Research has shown that age, gender, organizational tenure, and education level are all often associated with person-job fit, intrinsic motivation and job performance (e.g., Wayne and Linden, 1995; Cable and DeRue, 2002; Treadway, Hochwarter, Kacmar and Ferris, 2005), so the 
subordinate's age, gender, organizational tenure and education level were all controlled for in this study. Age and organizational tenure were self-reported in years. Gender was represented by a dummy, with male coded as "0" and female coded as "1." The education level dummy coded a middle school diploma or below as " 1 ," a high school diploma as " 2 ," a junior college degree as "3," bachelor's degree as "4," and a postgraduate degree as " 5 ," respectively.

\section{Results}

\subsection{Confirmatory Factor Analysis}

Confirmatory factor analyses (CFAs) were conducted to evaluate the distinctiveness of all multiple-item variables. We first examined a four-factor CFA model in which employee experienced HPWPs, person-job fit, intrinsic motivation and job performance were all included. The model fitted the data well: $\chi^{2}(455)=866.25, p \leqslant 0.01 ; \mathrm{CFI}=0.91$, TLI $=0.91$; RMSEA $=0.053$. In addition, all the path loadings from the latent constructs were significant, confirming convergent validity.

The discriminant validity of the four constructs was then tested by contrasting a four-factor model against one-factor and three-factor models. We combined person-job fit and intrinsic motivation to form the three-factor model because their correlation was the highest among the four constructs. Table 2 indicates that the hypothesized four-factor model fitted the data significantly better than the two alternative nested models based on the comparisons of the chi-square and degree of freedom $(p \leqslant 0.01)$. Thus, the discriminant validity of the constructs was confirmed and all of the proposed constructs were applied in further analyses.

Table 2 Results of Confirmatory Factor Analysis for the Measures of the Variables Studied

\begin{tabular}{|c|c|c|c|c|c|c|}
\hline Model & $X^{2}$ & $d f$ & $\Delta X^{2}$ & CFI & TLI & RMSEA \\
\hline Four factor model & 866.25 & 455 & & 0.91 & 0.91 & 0.053 \\
\hline $\begin{array}{l}\text { Three factor model: Person-job fit } \\
\text { and intrinsic motivation combined }\end{array}$ & 973.13 & 458 & $106.88(3)$ & 0.89 & 0.88 & 0.060 \\
\hline One factor model & 2924.80 & 464 & $2058.55(9)$ & 0.48 & 0.44 & 0.129 \\
\hline
\end{tabular}

\subsection{Descriptive Statistics}

Table 3 presents the means, standard deviations, and zero-order Pearson correlations of all the major variables. As the table shows, employee experienced 
HPWPs were positively correlated with person-job fit, intrinsic motivation and extrinsically rated job performance $(r=0.30,0.31$, and 0.18 , respectively, each $p \leqslant 0.01)$. As expected, person-job fit $(r=0.34, p \leqslant 0.01)$ and intrinsic motivation $(r=0.37, p \leqslant 0.01)$ were positively correlated with job performance, but note that the correlation coefficients were significantly larger than the correlation coefficient between employee experienced HPWPs and job performance, indicating a potential mediating role for person-job fit and intrinsic motivation. Finally, organizational tenure $(r=0.13, p \leqslant 0.05)$ and education level $(r=0.15, p \leqslant 0.01)$ were both positively correlated with job performance, as might be expected.

Table 3 Means, Standard Deviations, and Correlations

\begin{tabular}{lcccccccc}
\hline Variables & 1 & 2 & 3 & 4 & 5 & 6 & 7 & 8 \\
\hline 1. Age & & & & & & & & \\
2. Gender & -0.01 & & & & & & & \\
3. Organizational tenure & $0.44^{* *}$ & 0.01 & & & & & & \\
4. Education level & 0.05 & -0.01 & 0.06 & & & & & \\
5. Employee experienced & $-0.16^{* *}$ & 0.02 & -0.01 & -0.05 & $\mathbf{( 0 . 9 2 )}$ & & & \\
$\quad$ HPWPs & -0.05 & 0.02 & 0.06 & 0.03 & $0.30^{* *}$ & $(\mathbf{0 . 7 2 )}$ & & \\
6. Person-job fit & -0.04 & 0.04 & 0.06 & 0.08 & $0.31^{* *}$ & $0.52^{* *}$ & $(\mathbf{0 . 8 7})$ & \\
7. Intrinsic motivation & 0.06 & 0.02 & $0.13^{*}$ & $0.15^{* *}$ & $0.18^{* *}$ & $0.34^{* *}$ & $0.37^{* *}$ & $\mathbf{( 0 . 8 5 )}$ \\
8. Job performance & 32.66 & 0.36 & 4.80 & 2.89 & 3.55 & 3.61 & 3.62 & 3.62 \\
\hline Mean & 5.66 & 0.48 & 3.16 & 0.87 & 0.67 & 0.65 & 0.68 & 0.66 \\
S.D. & & & & & & & & \\
\hline
\end{tabular}

Note: $1 . N=318 ; *(* *)$ represents significant at the $p \leqslant 0.05(p \leqslant 0.01)$ level.

2. Values in brackets on the diagonal are Cronbach's alpha for each scale.

\subsection{Tests of Hypotheses}

Hierarchical multiple regression analyses were applied to test the hypotheses. The variables were entered into the regressions in three steps: the control variables were entered first (step 1), followed by the predictor (employee experienced HPWPs) in step 2 and the two mediators (person-job fit and intrinsic motivation) in step 3 . Table 4 presents the results. As shown in the table (see Model 6), employee experienced HPWPs were positively related to job performance $(\beta=0.20, p \leqslant 0.01)$; thus, $\mathrm{H} 1$ was supported.

$\mathrm{H} 2$ predicted that person-job fit mediates the relationship between employee experienced HPWPs and job performance, while $\mathrm{H} 3$ predicted that intrinsic motivation also mediates that relationship. Full mediation is normally considered supported if four conditions are met: (1) the independent variable (in this case 
employee experienced HPWPs) is significantly related to the mediators (i.e., person-job fit and intrinsic motivation); (2) the independent variable is significantly related to the dependent variable (i.e., job performance); (3) the mediators are significantly related to the dependent variable after entering the control and independent variables; and (4) when both controls and mediators are present, the relationship between the independent and the dependent variable becomes non-significant (Baron and Kenny, 1986).

Table 4 The Mediating Effects of Person-Job Fit and Intrinsic Motivation on the Relationship between Employee Experienced HPWPs and Job Performance

\begin{tabular}{|c|c|c|c|c|c|c|c|c|}
\hline & \multicolumn{2}{|c|}{ Person-job fit } & \multicolumn{2}{|c|}{$\begin{array}{l}\text { Intrinsic } \\
\text { motivation }\end{array}$} & \multicolumn{4}{|c|}{ Job performance } \\
\hline & $\begin{array}{c}\text { Model } \\
1\end{array}$ & $\begin{array}{c}\text { Model } \\
2\end{array}$ & $\begin{array}{c}\text { Model } \\
3\end{array}$ & $\begin{array}{c}\text { Model } \\
4\end{array}$ & $\begin{array}{l}\text { Model } \\
5\end{array}$ & $\begin{array}{l}\text { Model } \\
6\end{array}$ & $\begin{array}{c}\text { Model } \\
7\end{array}$ & $\begin{array}{c}\text { Model } \\
8\end{array}$ \\
\hline \multicolumn{9}{|l|}{ Control variables } \\
\hline Age & -0.09 & -0.03 & -0.08 & -0.02 & 0.00 & 0.04 & 0.04 & 0.05 \\
\hline Gender & 0.02 & 0.02 & 0.04 & 0.04 & 0.02 & 0.01 & 0.00 & 0.00 \\
\hline Organizational tenure & 0.10 & 0.08 & 0.10 & 0.07 & $0.12^{*}$ & 0.11 & 0.08 & 0.08 \\
\hline Education level & 0.03 & 0.04 & 0.08 & 0.10 & $0.15^{* *}$ & $0.15^{* *}$ & $0.12^{*}$ & $0.12^{*}$ \\
\hline \multicolumn{9}{|l|}{ Independent variable } \\
\hline $\begin{array}{l}\text { Employee experienced } \\
\text { HPWPs }\end{array}$ & & $0.29^{* *}$ & & $0.32^{* *}$ & & $0.20^{* *}$ & & 0.07 \\
\hline \multicolumn{9}{|l|}{ Mediators } \\
\hline Person-job fit & & & & & & & $0.20^{* *}$ & $0.19^{* *}$ \\
\hline Intrinsic motivation & & & & & & & $0.26^{* *}$ & $0.24^{* *}$ \\
\hline$\overline{R^{2}}$ & 0.01 & 0.09 & 0.02 & 0.12 & 0.04 & 0.08 & 0.19 & 0.20 \\
\hline$\Delta R^{2}$ & 0.01 & 0.08 & 0.02 & 0.10 & 0.04 & 0.04 & 0.15 & 0.12 \\
\hline$F$ & 0.90 & $6.50^{* *}$ & 1.43 & $8.00^{* *}$ & $3.12^{*}$ & $5.11^{* *}$ & $12.37^{* *}$ & $10.82^{* *}$ \\
\hline$\Delta F$ & 0.90 & $28.58^{* *}$ & 1.43 & $33.72^{* *}$ & $3.12^{*}$ & $12.57^{* *}$ & $29.72^{* *}$ & $23.28^{* *}$ \\
\hline
\end{tabular}

Note: $N=318 ; *(* *)$ indicates significant at the $p \leqslant 0.05(p \leqslant 0.01)$ level.

The results in Table 4 show that (1) employee experienced HPWPs were positively related to person-job fit $(\beta=0.29, p \leqslant 0.01$, Model 2$)$ and intrinsic motivation $(\beta=0.32, p \leqslant 0.01$, Model 4$)$; (2) employee experienced HPWPs were significantly related to job performance $(\beta=0.24, p \leqslant 0.01$, Model 6$)$; (3) person-job fit $(\beta=0.19, p \leqslant 0.01$, Model 8$)$ and intrinsic motivation $(\beta=0.24$, $p \leqslant 0.01$, Model 8 ) were both positively related to job performance after entering the control and independent variables; and (4) the relationship between employee experienced HPWPs and job performance lost its significance when both controls and the mediators were present (Model 8). Thus, Hypotheses 2 and 3 were also 
supported.

Although Baron and Kenny (1986) devised the most widely used procedures for testing mediation, their method does not test whether or not the mediating effect is significantly different from zero (Shrout and Bolger, 2002). To establish this, we performed Sobel tests (Sobel, 1982). Two Sobel tests substantiated that the mediating effects of both person-job fit $(Z=2.69, p<0.01)$ and intrinsic motivation $(Z=3.27, p<0.01)$ were significant in the relationship between employee experienced HPWPs and job performance. These results provided further support for Hypotheses 2 and 3.

\section{Discussion}

We hypothesized and found that employee experienced HPWPs positively influence individual job performance. Moreover, this relationship was found to be fully mediated by person-job fit and intrinsic motivation.

\subsection{Theoretical Implications}

Our research makes several contributions. First, unlike most prior studies of HPWPs, which examine HPWPs-performance linkage at the organizational level, this study takes perspective of employee and examines the relationship between employee experienced HPWPs and employee job performance. Consistent with few of the previous findings (Lepak et al., 2006; Liao et al., 2009), our findings indicate that individual employee's experience of HPWPs does differ from one to another within an organization. Moreover, we found that employee experienced HPWPs promotes individual job performance. As a result, we contribute to the HPWPs literature by demonstrating the performance implications of employee experienced HPWPs.

Second, starting from Huselid's (1995) theoretical arguments, we found that person-job fit and intrinsic motivation act as important intervening mechanisms that mediate the relationship between employee experienced HPWPs and individual job performance. Such important findings enrich the HPWPs literature by uncovering the mechanism through which employee experienced HPWPs positively impact individual job performance. Moreover, the findings on the connections between employee experienced HPWPs and person-job fit and intrinsic motivation also contribute to the research on the antecedents of person-job fit and intrinsic motivation, which largely overlooks the impact of HR practices, especially HPWPs.

Finally, the methodological design of this study strengthens its contributions. First, the collection of data at three distinct points in time leads some support to the causal nature of the model. In addition, the use of data collected from two 
different sources helps limit potential problems associated with common method bias (Podsakoff et al., 2003).

\subsection{Managerial Implications}

This model and the empirical findings have important implications for managers. As an effective HRM system, HPWPs are being widely adopted in firms globally. How to implement HPWPs so as to benefit the bottom line is a topic gaining increasing attention among business practitioners. Our findings indicate that there are significant variations in employee experienced HPWPs within a firm, and that employee experienced HPWPs promotes the employee's person-job fit and intrinsic motivation, which in turn enhance his or her job performance. Hence, to improve employee job performance, HPWPs should be adopted in organizations. Research on the antecedents of HPWPs has found that management HRM values, market orientation, and HRM competency are all positively related to the adoption of HPWPs (Lewin and Yang, 1992; Wei and Lau, 2005). Thus, to facilitate the adoption of SHRM, the top management must see the value of HRM and the organization should adopt market orientation strategy and improve the overall capabilities of HR managers and professionals.

Moreover, merely adoption of HPWPs is not enough. The HPWPs should be implemented effectively across different departments, groups and hierarchical levels to ensure that most of the employees fit their jobs well and have high levels of intrinsic motivation. To this point, we encourage top managers (especially the CEOs and chief HR managers), middle managers, and employees to actively participate in the design and implementation of HPWPs because without their active participation, HPWPs are unlikely to generate significant impact in organizations. Finally, since person-job fit and intrinsic motivation are important predictors of employee job performance, in addition to HPWPs, organizations should take other measures such as building a supportive and learning oriented culture to enhance employee person-job fit and intrinsic motivation.

\subsection{Limitations and Future Research}

This study has some limitations. First, although the data analyzed here came from two sources, it may still have been susceptible to common method variance, as we asked each subordinate to report not only on his or her experienced HPWPs, but also on person-job fit and intrinsic motivation (Podsakoff et al., 2003). However, the three-wave research design and the construct validity tests indicate that common method bias was not likely to have determined our findings. 
Second, several demographic variables were controlled for in an attempt to partial out any potential confounding effects on employee job performance, but because of data limitations we could not include a few potentially important variables such as leadership behaviors and employee personality traits. Some such variables have been identified in previous research as having strong relationships with employee job performance (Barrick and Mount, 1991; Wang, Law, Hackett, Wang and Chen, 2005). Further investigations are needed to verify the incremental effects of employee experienced HPWPs, person-job fit and intrinsic motivation above and beyond the major factors that influence employee job performance.

Third, although this research investigated the mediating roles of intrinsic motivation and person-job fit on the relationship between employee-experienced HPWPs and individual job performance, it should also be noted that there may have other important mediators. For example, high performance work practices, such as provision of job security, extensive skills training, and broad career paths, signal an organization's intention to establish a long-term exchange relationship with the employee, which helps develop a high-quality, open-ended relationship between the organization and the employee. Under the norm of reciprocity (Blau, 1964), the employee is likely to contribute more in return such as a higher level of job performance. Hence, future research can explore whether the social exchange relationship between the organization and the employee (i.e., perceived organization support) mediates the relationship between employee-experienced HPWPs and individual job performance.

Despite these limitations, the present study has provided some insights into crucial issues regarding the impact of employee experienced HPWPs in organizations. It has revealed that employee experienced HPWPs positively influence the employee's person-job fit and intrinsic motivation, which in turn enhance his or her job performance. We hope that our study will stimulate future research to advance the theoretical understandings of how employee experienced HPWPs influence individual work outcomes in organizations.

Acknowledgements This work was partially supported by the National Natural Science Foundation of China via a research grant (No. 70572018) to the third author.

\section{References}

Appelbaum, E., Bailey, T., Berg, P., \& Kalleberg, A. L. 2000. Manufacturing advantage: Why high performance work systems pay off. Ithaca, NY: Cornell University Press.

Arthur, J. B. 1994. Effects of human resource systems on manufacturing performance and turnover. Academy of Management Journal, 37(3): 670-687.

Bae, J., \& Lawler, J. J. 2000. Organizational and HRM strategies in Korea: Impact on firm 
performance in an emerging economy. Academy of Management Journal, 43(3): 502-517.

Barney, J. B., \& Wright, P. M. 1998. On becoming a strategic partner: The role of human resources in gaining competitive advantage. Human Resources Management, 37(1): 31-46.

Baron, R. M., \& Kenny, D. A. 1986. The moderator-mediator variable distinction in social psychological research: Conceptual, strategic, and statistical consideration. Journal of Personality and Social Psychology, 57(6): 1173-1182.

Barrick, M. R., \& Mount, M. K. 1991. The big five personality dimensions and job performance: A meta-analysis. Personnel Psychology, 44(1): 1-26.

Bartel, A. P. 2004. Human resource management and organizational performance: Evidence from retail banking. Industrial and Labor Relations Review, 57(2):181-203.

Batt, R. 2002. Managing customer services: Human resource practices, quit rates and sales growth. Academy of Management Journal, 45(3): 587-597.

Becker, B. E., \& Huselid, M. A. 1998. High performance work systems and firm performance: A synthesis of research and managerial implications. Research in Personnel and Human Resource Management, 16: 53-101.

Blau, P. M. 1977. Inequality and heterogeneity. New York: Free Press.

Boxall, P. 1996. The strategic HRM debate and the resource-based view of the firm. Human Resource Management Journal, 6(3): 59-75.

Brislin, R. W. 1980. Translation and content analysis of oral and written material. In H. C. Triandis \& J. W. Berry (Eds.), Handbook of cross-cultural psychology: 389-444. Boston: Allyn \& Bacon.

Brousseau, K. R. 1984. Job-person dynamics and career development. In B. M. Staw \& L. L. Cummings (Eds.), Research in organizational behavior: 125-154. Greenwich, CT: JAI Press.

Cable, D. M., \& DeRue, D. S. 2002. The convergent and discriminant validity of subjective fit perceptions. Journal of Applied Psychology, 87(5): 875-884.

Caldwell, D. F., \& O’Reilly, C. A. 1990. Measuring person-job fit within a profile comparison process. Journal of Applied Psychology, 75(6): 648-657.

Deci, E., \& Ryan, R. 2002. Handbook of Self-Determination Research. Rochester, NY: University of Rochester Press.

Deci, E. L., \& Ryan, R. M. 2000. The "what" and "why" of goal pursuits: Human needs and the self-determination of behavior. Psychological Inquiry, 11(4): 227-268.

Delery, J. E., \& Doty, D. H. 1996. Modes of theorizing in strategic human resource management: Tests of universalistic, contingency, and configurational perspectives. Academy of Management Journal, 39(4): 802-835.

Delery, J. E., \& Shaw, J. D. 2001. The strategic management of people in work organizations: Review, synthesis and extension. In K. M. Rowland and G. R. Ferris (Eds.), Research in personnel and human resource management: 165-197. Greenwich, CT: JAI Press.

Edwards, J. R. 1991. Person-job fit: A conceptual integration, literature review, and methodological critique. In C. L. Cooper \& I. T. Robertson (Eds.), International review of industrial and organizational psychology: 283-357. New York: Wiley.

Gagné, M., \& Deci, E. L. 2005. Self-determination theory and work motivation. Journal of Organizational Behavior, 26(4): 331-362. 
Gerhart, B., Wright, P. M., \& McMahan, G. C. 2000. Measurement error in research on the human resources and firm performance relationship: Further evidence and analysis. Personnel Psychology, 53(4): 855-872.

Guest, D. E. 1998. Is the psychological contract worth taking seriously? Journal of Organizational Behavior, 19: 649-664.

Guthrie, J. P. 2001. High-involvement work practices, turnover, and productivity: Evidence from New Zealand. Academy of Management Journal, 44(1): 180-190.

Hackman, J. R., \& Oldham, G. R. 1980. Work redesign. Reading, MA: Addison-Wesley.

Hair, J. F., Anderson, R. E., Tatham, R. L., \& Black, W. C. 1998. Multivariate Data Analysis. Upper Saddle River, NJ: Prentice-Hall.

Harley, B., Allen, B. C., \& Sargent, L. D. 2007. High performance work systems and employee experience of work in the service sector: The case of aged care. British Journal of Industrial Relations, 45(3):607-633.

Hui, C., Law, K. S., \& Chen, Z. X. 1999. A structural equation model of the effects of negative affectivity, leader-member exchange and perceived job mobility on in-role and extra-role performance: A Chinese case. Organizational Behavior and Human Decision Processes, 77: 3-21.

Huselid, M. A. 1995. The impact of human resource management practices on turnover, productivity, and corporate financial performance. Academy of Management Journal, 38(3): 635-672.

Kristof, A. L. 1996. Person-organization fit: An integrative review of its conceptualizations, measurement, and implications. Personnel Psychology, 49(1): 1-49.

Lepak, D. P., Liao, H., Chung, Y., \& Harden, E. E. 2006. A conceptual review of HR management systems in strategic HRM research. In J. J. Martocchio (Ed.), Research in Personnel and Human Resource Management: 217-272. New York: Wiley.

Lewin, D., \& Yang, J. Z. 1992. HRM policies and practices of U.S. and Japanese firms operation in the U.S. In J. F. Burton, Jr. (Eds.). Proceedings of the 44th annual meeting of industrial relations research association.

Liao, H., Toyo, H., Lepak, A. P., \& Hong, Y. 2009. Do they see eye to eye? Management and employee perspectives of high performance work systems and influence processes on service quality. Journal of Applied Psychology, 94(2): 371-391.

MacDuffie, J. P. 1995. Human resource bundles and manufacturing performance: Organizational logic and flexible production systems in the world auto industry. Industrial and Labor Relations Review, 48(2): 197-221.

Motowidlo, S. J. 2003. Job performance. In W. C. Borman, D. R. Ilgen, \& R. J. Klimoski (Eds.), Handbook of Psychology: Industrial and Organizational Psychology: 39-53. Hoboken, NJ: John Wiley \& Sons.

Pfeffer, J., \& Veiga, J. F. 1999. Putting people first for organizational success. Academy of Management Executive, 13(2): 37-48.

Piccolo, R. F., \& Colquitt, J. A. 2006. Transformational leadership and job behaviors: The mediating role of core job characteristics. Academy of Management Journal, 49(2): 327-340.

Podsakoff, P. M., MacKenzie, S. B., Lee, J. S., \& Podsakoff, N. P. 2003. Common method 
biases in behavioral research: A critical review of the literature and recommended remedies. Journal of Applied Psychology, 88(5): 879-903.

Ramsay, H., Dora, S., \& Harley, L. 2000. Employees and high performance work systems: Testing inside the black box. British Journal of Industrial Relations, 41(2): 501-531.

Rousseau, D. M. 2005. I-deals: Idiosyncratic deals employees bargain for themselves. Armonk, NY: M. E. Sharpe.

Shore, L. M., \& Barksdale, K. 1998. Examining degree of balance and level of obligation in the employment relationship: A social exchange approach. Journal of Organizational Behavior, 19(7): 731-744.

Shrout, P. E., \& Bolger, N. 2002. Mediation in experimental and nonexperimental studies: New procedures and recommendations. Psychological Methods, 7(4): 422-445.

Sobel, M. E. 1982. Asymptotic confidence intervals for indirect effects in structural equation models. In S. Leinhardt (Ed.), Sociological Methodology: 290-312. Washington, DC: American Sociological Association.

Sun, L. Y., Aryee, S., \& Law, K. S. 2007. High-performance human resource practices, citizenship behavior, and organizational performance: A relational perspective. Academy of Management Journal, 50(3): 558-577.

Takeuchi, R., Chen, G., \& Lepak, D. P. 2009. Through the looking glass of a social system: Cross-level effects of high-performance work systems on employees' attitudes. Personnel Psychology, 62(1): 1-29.

Takeuchi, R., Lepak, D. P., Wang, H., \& Takeuchi, K. 2007. An empirical examination of the mechanisms mediating between high performance work systems and the performance of Japanese organizations. Journal of Applied Psychology, 92(4): 1069-1083.

Treadway, D. C., Hochwarter, W. A., Kacmar, C. J., \& Ferris, G. R. 2005. Political will, political skill, and political behavior. Journal of Organizational Behavior, 26(3): 229-245.

Tsui, A. S., Pearce, J. L., Porter, L. W., \& Tripoli, A. M. 1997. Alternative approaches to the employee-organization relationship: Does investment in employees pay off? Academy of Management Journal, 40(5): 1089-1121.

Vallerand, R. J. 1997. Toward a hierarchical model of intrinsic and extrinsic motivation. In M. P. Zanna (Ed.), Advances in Experimental Social Psychology: 271-360. New York: Academic Press.

Wang, H., Law, K. S., Hackett, R., Wang, D. X., \& Chen, Z. X. 2005. Leader-member exchange as a mediator of the relationship between transformational leadership and followers' performance and organizational citizenship behavior. Academy of Management Journal, 48(3): 420-432.

Warr, P., Cook, J., \& Wall, T. 1979. Scales for the measurement of some work attitudes and aspects of psychological well being. Journal of Occupational Psychology, 52(2): 129-148.

Wayne, S. J., \& Liden, B. C. 1995. Effects of impression management on performance ratings: A longitudinal study. Academy of Management Journal, 38(1): 232-260.

Wei, L.Q., \& Lau, C.M. 2005. Market orientation, HRM importance and HRM competency: Determinants of Strategic HRM in Chinese Firms. International Journal of Human Resource Management, 16(10): 1901-1918.

Williams, L. J., \& Anderson, S. E. 1991. Job satisfaction and organizational commitment as 
predictors of citizenship and in-role behaviors. Journal of Management, 17: 601-617.

Wright, P. M., \& Boswell, W. R. 2002. Desegregating HRM: A review and synthesis of micro and macro human resource research. Journal of Management, 28(3): 247-276.

Wright, P. M., Dunford, B., \& Snell, S. A. 2001. Human resources and the resource based view of the firm. Journal of Management, 27(6): 702-721. 